\title{
The Ross procedure: Outcomes at 20 years
}

\author{
Tirone E. David, MD, Carolyn David, BN, Anna Woo, MD, and Cedric Manlhiot, BSc
}

Objectives: Our study examines the outcomes of the Ross procedure in a cohort of 212 patients prospectively followed with clinical and echocardiographic assessments.

\begin{abstract}
Methods: Patients' mean age was $34 \pm 9$ years; $66 \%$ were men and $82 \%$ had congenital aortic valve disease. The median follow-up was 13.8 years. Patients who had reoperations continued to be followed and entered into the survival analysis.

Results: There was 1 operative death as well as 9 late deaths ( 3 in patients who no longer had the Ross). Survival at 20 years was $93.6 \%$ and similar to the general population matched for age and sex. Fifteen patients required reoperations on the pulmonary autograft (4 repairs and 11 replacements), 8 on the pulmonary homograft, and 4 other cardiac procedures. At 20 years the freedom from reoperation on the pulmonary autograft was $81.8 \%$ and on the pulmonary homograft was $92.7 \%$, and in both was $79.9 \%$. Preoperative aortic insufficiency, aortic annulus diameter $\geq 15 \mathrm{~mm} / \mathrm{m}^{2}$, and being a man were associated with increased risk of reoperation on the pulmonary autograft. Twenty-six patients developed aortic insufficiency greater than mild and 25 patients developed pulmonary homograft dysfunction (defined as moderate or severe insufficiency and/or peak systolic gradient of $>40 \mathrm{~mm} \mathrm{Hg}$ ). At 20 years the freedom from aortic insufficiency was $62.6 \%$ and freedom from pulmonary valve dysfunction was $53.5 \%$.
\end{abstract}

Conclusions: Survival after the Ross procedure in this cohort was similar to the general population. Dilated aortic annulus and aortic insufficiency were associated with increased risk of developing aortic insufficiency. Pulmonary homograft dysfunction was common at 20 years. (J Thorac Cardiovasc Surg 2014;147:85-94)

The usefulness of the Ross procedure remains controversial. ${ }^{1-10}$ Some surgeons believe it is an excellent option in children or young adults regardless of the aortic valve pathology, ${ }^{8-10}$ whereas others have shown worrisome failure rates during the second decade of follow-up, ${ }^{4}$ particularly in patients with incompetent bicuspid aortic valve. ${ }^{5-7}$ Dilation of the neo-aortic root was thought to be the principal cause of failure of the pulmonary autograft ${ }^{11,12}$ but further experience with reoperations indicated that degeneration of the neo-aortic valve was a common pathologic finding regardless of the technique used for its transfer into the aortic position. ${ }^{5,6,13}$ Thus, performance of aortic valve sparing operations to preserve the pulmonary autograft is not always feasible in patients who developed aortic insufficiency (AI). ${ }^{6,13,14}$ Moreover, the durability of aortic valve sparing operations after the Ross procedure remains unknown. Finally, not only the pulmonary autograft may have limited durability but also the valve

\footnotetext{
From the Cardiac Program, Peter Munk Cardiac Centre at Toronto General Hospital and University of Toronto, Toronto, Ontario, Canada.

Disclosures: Authors have nothing to disclose with regard to commercial support.

Read at the 93rd Annual Meeting of The American Association for Thoracic Surgery, Minneapolis, Minnesota, May 4-8, 2013.

Received for publication April 16, 2013; revisions received July 15, 2013; accepted for publication Aug 3, 2013; available ahead of print Sept 30, 2013.

Address for reprints: Tirone E. David, MD, 200 Elizabeth St, 4N453, Toronto,

Ontario M5G 2C4, Canada (E-mail: tirone.david@uhn.ca).

$0022-5223 / \$ 36.00$

Copyright (c) 2014 by The American Association for Thoracic Surgery

http://dx.doi.org/10.1016/j.jtcvs.2013.08.007
}

used to replace the pulmonary valve fails, compounding the problem of reoperations in patients with failed Ross procedure. $^{14,15}$

Our study examines the outcomes of the Ross procedure in a cohort of patients who have been prospectively followed with periodical echocardiographic assessment of valve function to further elucidate the late outcomes of this controversial operation to treat aortic valve disease in young adults.

\section{METHODS}

From 1990 to 2004, 212 consecutive patients underwent the Ross operation performed by 1 surgeon and were prospectively followed annually during the first decade and biennially thereafter. Echocardiography was used for periodical assessment of valve function and aortic root dimensions. Table 1 shows the clinical profile of all patients. The operative techniques used in these patients were described in a previous article. ${ }^{6}$ Basically, the pulmonary autograft was secured in the aortic position using a modified subcoronary implantation or aortic root inclusion in 104 patients and as a freestanding neo-aortic root in 108 patients. The decision to use an inclusion technique (subcoronary or root inclusion) or root replacement was largely dependent on the pathology of the aortic root, sizes of the native aortic root and pulmonary root, and anatomy of the coronary arteries. Thus, patients with small aortic root, previous aortic valve surgery, or anomalous right coronary artery orifice (the orifice was too close to the aortic annulus for subcoronary implantation) often had aortic root replacement, whereas those with normal or dilated aortic roots had inclusion techniques. The noncoronary aortic sinus was always opened down to the level of the annulus when inclusion techniques were used to improve exposure and facilitate implantation of the pulmonary autograft. The diameters of the annulus and sinotubular junction of the pulmonary and aortic roots were recorded and surgical adjustments were made before implantation of the pulmonary valve in the aortic position if the aortic annulus was greater 


\section{Abbreviation and Acronym \\ $\mathrm{AI}=$ aortic insufficiency}

than the pulmonary annulus by more than 2 to $3 \mathrm{~mm} \cdot{ }^{6-16}$ The techniques used to reduce the aortic annulus have been previously published. ${ }^{16}$

\section{Follow-up}

The referring cardiologists followed the patients and provided annual clinical and echocardiographic data. The echocardiographic study was repeated in our hospital whenever the report indicated moderate or severe AI or pulmonary valve dysfunction (moderate or severe insufficiency or a peak systolic gradient $>40 \mathrm{~mm} \mathrm{Hg}$ ). For this study, the follow-up was closed on November 1, 2012, and was complete in 202 patients. The remaining 9 patients had partial echocardiographic follow-up because we could not get studies due to geographic location. The median duration of the clinical follow-up was 13.8 years; interquartile range (IQR), 10.6 to 17.1 years; and was $100 \%$ complete. The median duration of the echocardiographic follow-up was 13.2 years; IQR, 9.1 to 16.1 years; 9 patients did not have a study during the past 1 to 3 years. AI and pulmonary insufficiency was initially graded based on color flow Doppler, ${ }^{17}$ and since 2003 the guidelines of the American Society of Echocardiography were adopted. ${ }^{18}$ Patients who had any reoperation continued to be followed and were included into the survival analysis to compare survival of Ross patients with that of the general population matched for sex and age.

\section{Statistical Analysis}

All variables in Tables 1 and 2 were examined. Variables with rare frequencies $(<2.5 \%$ or $<20$ events) were reported in the descriptive statistics but were either collapsed (when possible) or excluded from all risk factor analyses (ie, timing of surgery, previous cardiac operations, angina pectoris, and endocarditis). Data are presented as means with standard deviations, median with IQR, and frequencies, as appropriate. Potential cut points for increased risk of outcomes based on aortic annulus size were tested in logistic regression models. From these models, receiver operating characteristic curves were created in which the sensitivity and specificity of all potential cut points was evaluated to identify the cut point with the most accurate segregation of patients by outcome. Additionally, probability function derived from the logistic regression model was graphed to visually represent the change in probability of outcome based on aortic annulus size. Life tables from the Province of Ontario from 2000-2002 $2^{19}$ were used to estimate 20-year survival of the patient cohort according to age and sex distribution.

Freedom from time-dependent outcomes was modeled in parametric survival models (using maximum likelihood estimates to resolve risk) that divide risk over time in up to 3 distinct phases of risk (early, constant, and late) using standard mathematical algorithms from the HAZARD procedure (http://www.clevelandclinic.org/heartcenter/hazard). The parametric survival models were combined to obtain prevalence of mutually exclusive events (reoperation all causes and mortality all causes). All associations between freedom from outcomes and potential predictors were first screened in univariable models. Associations between patient and surgical characteristics and outcomes were included in a bootstrap bagging algorithm (500 resamples). Variables with high reliability $(>50 \%$ ) (defined as percent of resample in which a given variable is selected) were then included in a multivariable parametric survival regression model with backward selection of variables to obtain a final model. All risk factors analyses were performed using a unified phase of risk given the limited number of event in some phases of risk. Because of the low number of events for most models, the multivariable models have limited reliability and we used instead univariable associations. Mean imputation was used to account for missing variables. Progression of aortic sinus dimension over time was modeled in linear regression models adjusted for repeated measures over time through a compound symmetry covariance structure. All statistical analyses were performed using SAS version 9.3 (SAS Institute Inc, Cary, NC).

\section{RESULTS \\ Patients' Survival}

There was 1 operative death as well as 9 late deaths. The only operative death was due to myocardial infarction and it is depicted in Figure 1, $A$. Three of the late deaths occurred in patients who no longer had the pulmonary autograft in the aortic position. The causes of late deaths were valve-related in 3 patients (sudden death in all 3 patients) and noncardiac related in 6 patients. The survival of the entire cohort of Ross patients, including those who had reoperations for any cause is shown Figure 1, $A$, and it is only slightly lower than the survival of the general population matched for sex and age (odds ratio for death in cohort vs population, $1.7 ; 95 \%$ confidence interval $[\mathrm{CI}], 0.6-4.5 ; P=.37$ ). Figure $1, B$, shows survival free from reoperation on the pulmonary autograft or homograft and the competing risk of death and any reoperation. Survival of the entire cohort at various times intervals is shown in Table 2.

\section{Thromboembolic Complications}

Two patients experienced a stroke with complete recovery and 2 experienced a transient ischemic attack. The freedom from this complication at various times intervals is shown in Table 2.

\section{Infective Endocarditis}

Four patients developed infective endocarditis of the pulmonary homograft and none in the pulmonary autograft. Two patients were successfully treated with antibiotics alone and 2 required surgery. One of the patients who required surgery also had moderate AI and both the pulmonary homograft and autograft were replaced at the same operation. The second patient had pulmonary homograft replacement and tricuspid valve repair. In addition, 1 of 2 patients who developed endocarditis needed pulmonary valve replacement 4 years later because of severe pulmonary insufficiency. The freedom from infective endocarditis at various time intervals is shown in Table 2.

\section{Hemorrhagic Complications}

There was no major hemorrhagic event. At the final follow-up contact 62 patients were taking aspirin and none were receiving warfarin.

\section{Reoperations}

Twenty-five patients required 1 or more reoperations or transcatheter pulmonary valve implantation. Fifteen patients had reoperation on the neo-aortic valve: 13 for AI (11 patients had valve replacement and 2 patients had valve 
TABLE 1. Clinical profile and operative procedures

\begin{tabular}{|c|c|}
\hline Variables & Result \\
\hline Age at surgery, median y (IQR) & $34(28-41)$ \\
\hline$\leq 25$ & $38(17.9)$ \\
\hline $26-35$ & $76(35.9)$ \\
\hline $36-45$ & $70(33.0)$ \\
\hline$>45$ & $28(13.2)$ \\
\hline Men & $140(66.0)$ \\
\hline \multicolumn{2}{|l|}{ Year } \\
\hline$\leq 1994$ & $52(24.5)$ \\
\hline 1995-1999 & $95(44.8)$ \\
\hline 2000-2004 & $65(30.7)$ \\
\hline \multicolumn{2}{|l|}{ Previous cardiac interventions } \\
\hline Previous aortic valve surgery & $30(14.2)$ \\
\hline Previous mitral valve repair & $1(0.5)$ \\
\hline Previous cardiac surgery (not listed above) & $12(5.7)$ \\
\hline Any previous cardiac surgery & $37(17.5)$ \\
\hline \multicolumn{2}{|l|}{ Clinical presentation } \\
\hline \multicolumn{2}{|l|}{ Timing of surgery } \\
\hline Elective & $192(90.6)$ \\
\hline Same hospitalization & $13(6.1)$ \\
\hline Urgent/emergent ( $<72 \mathrm{~h}$ from acute cardiac event) & $7(3.3)$ \\
\hline Angina & $39(18.4)$ \\
\hline \multicolumn{2}{|l|}{ NYHA functional class } \\
\hline I & $41(19.3)$ \\
\hline II & $135(63.7)$ \\
\hline III & $26(12.3)$ \\
\hline IV & $10(4.7)$ \\
\hline \multicolumn{2}{|l|}{ Left ventricular ejection fraction } \\
\hline$\geq 60 \%$ & $127(60.0)$ \\
\hline $40 \%-59 \%$ & $67(31.6)$ \\
\hline $20 \%-39 \%$ & $18(8.5)$ \\
\hline Congestive heart failure & $34(16.0)$ \\
\hline Shock & $0(0.0)$ \\
\hline Atrial fibrillation or flutter & $1(0.5)$ \\
\hline Complete heart block/pacemaker & $1(0.5)$ \\
\hline Syncope & $19(9.0)$ \\
\hline \multicolumn{2}{|l|}{ Associated diseases } \\
\hline Hypertension & 29 (13.6) \\
\hline Hyperlipidemia & $20(9.4)$ \\
\hline Chronic obstructive pulmonary disease & $5(2.3)$ \\
\hline Previous stroke or transient ischemic attack & $8(3.8)$ \\
\hline Diabetes mellitus & $2(0.9)$ \\
\hline Endocarditis & $15(7.1)$ \\
\hline Healed & $13(6.3)$ \\
\hline Active & $2(0.9)$ \\
\hline \multicolumn{2}{|l|}{ Pathology/pathophysiology } \\
\hline Mitral regurgitation & $4(1.9)$ \\
\hline \multicolumn{2}{|l|}{ Aortic valve lesion } \\
\hline Stenosis & $107(50.4)$ \\
\hline Insufficiency & $77(36.3)$ \\
\hline Mixed lesion & $28(13.2)$ \\
\hline \multicolumn{2}{|l|}{ Aortic valve pathology } \\
\hline Bicuspid & $152(71.7)$ \\
\hline Other congenital & $22(10.3)$ \\
\hline Prosthetic dysfunction & $10(4.7)$ \\
\hline Tricuspid calcific & $3(1.4)$ \\
\hline
\end{tabular}

TABLE 1. Continued

\begin{tabular}{lc}
\hline \multicolumn{1}{c}{ Variables } & Result \\
\hline Rheumatic & $6(2.8)$ \\
Miscellaneous & $19(9.0)$ \\
Operative data & \\
$\quad$ Aortic annular enlargement & $5(1.4)$ \\
$\quad$ Pulmonary valve size, mean mm \pm standard deviation & $27.2 \pm 1.4$ \\
Implantation technique & \\
Inclusion or subcoronary & $104(49.0)$ \\
Root replacement & $108(50.9)$ \\
Surgical reduction of the aortic root & \\
$\quad$ None & $90(42.7)$ \\
Aortic annulus & $61(28.9)$ \\
Sino-tubular junction & $25(11.9)$ \\
$\quad$ Aortic annulus + sino-tubular junction & $35(16.6)$ \\
Replacement of ascending aorta & $25(11.8)$ \\
Mitral valve repair & $4(1.9)$ \\
Crossclamp time, median min (IQR) & $123(114-133)$ \\
\hline
\end{tabular}

Data are presented as $\mathrm{n}(\%)$, unless otherwise indicated. $I Q R$, Interquartile range; NYHA, New York Heart Association.

repair) and 2 for a subaortic false aneurysm (both repaired with preservation of the pulmonary autograft). Twelve of 13 patients with AI that led to reoperation had AI before the Ross procedure. AI before the Ross procedure increased the risk of reoperation (hazard ratio [HR], 6.3; 95\% CI, 1.3-29.4; $P=.02$ ). All reoperations on the pulmonary autograft were in men. Male sex was associated with increased risk of reoperation (HR, 4.8; 95\% CI, 1.6-14.4; $P=.005$ ). Dilated aortic annulus index also increased the risk of reoperation (HR, 1.408/mm; 95\% CI, 1.2-1.6; $P<.001)$. The aortic annulus diameter cut-off associated with increased reoperation on the neo-aortic valve was $\geq 28 \mathrm{~mm}$ or $15 \mathrm{~mm} / \mathrm{m}^{2}$. Figure 2 shows the association between reoperation and the diameter of the aortic annulus. The technique of implantation of the pulmonary autograft had no effect on the risk of reoperation. Table 2 shows the freedom from reoperation on the neo-aortic valve for any cause at various times intervals as well as in patients with preoperative AI that included those with mixed lesions.

Eight patients required pulmonary homograft intervention either combined with pulmonary autograft surgery ( 2 patients) or in isolation (6 patients). Five patients underwent pulmonary valve re-replacement and 3 underwent transcatheter valve implantation. One patient required reoperation on the pulmonary valve twice. There was no association between any variable examined and pulmonary homograft intervention.

Finally, 1 patient had isolated replacement of the ascending aorta for aneurysm (the neo-aortic valve was competent), and 3 patients underwent coronary artery bypass surgery. There was no operative death or any serious perioperative complication among the 25 patients who had reoperations or catheter-based pulmonary valve implantation. 
TABLE 2. Freedom from morbid events at various time intervals

\begin{tabular}{lcccc}
\hline \multicolumn{1}{c}{ Freedom from event } & $\mathbf{5} \mathbf{y}(\mathbf{9 5} \% \mathbf{C I})$ & $\mathbf{1 0 ~ y}(\mathbf{9 5} \% \mathbf{C I})$ & $\mathbf{1 5} \mathbf{y}(\mathbf{9 5} \% \mathbf{C I})$ & $\mathbf{2 0} \mathbf{y}(\mathbf{9 5} \% \mathbf{C I})$ \\
\hline All-cause mortality & $98.6(95.7-99.5)$ & $97.5(94.0-98.9)$ & $93.6(88.1-96.6)$ & $93.6(88.1-96.6)$ \\
Alive and reoperation-free on the AV or PV & $93.7(87.7-96.7)$ & $90.4(83.3-94.5)$ & $84.4(75.2-90.2)$ & $77.9(61.7-87.9)$ \\
Thromboembolism & $99.1(96.3-99.8)$ & $98.6(95.6-99.5)$ & $98.6(95.6-99.5)$ & $96.8(89.9-99.0)$ \\
Endocarditis & No event & $99.0(96.0-99.7)$ & $96.8(92.4-98.7)$ & $96.8(92.4-98.7)$ \\
Reoperation on AV & $97.6(94.3-99.0)$ & $96.5(92.8-98.3)$ & $93.0(87.3-96.1)$ & $81.8(60.3-92.3)$ \\
Reoperation on patients with aortic insufficiency & $95.2(88.8-98.0)$ & $94.1(87.4-97.3)$ & $87.3(77.0-93.2)$ & $75.5(52.0-88.7)$ \\
Reoperation on PV & No event & $97.9(94.5-99.2)$ & $95.5(90.5-97.9)$ & $92.7(85.6-96.4)$ \\
Aortic insufficieny* & $93.1(88.6-95.8)$ & $90.3(85.2-93.7)$ & $88.7(83.1-92.6)$ & $62.6(28.6-89.3)$ \\
PV dysfunction $\dagger$ & $93.0(88.4-95.8)$ & $84.8(78.8-89.2)$ & $74.6(78.8-89.2)$ & $53.8(30.7-72.2)$ \\
Aortic root $>44$ mm & $99.5(96.6-99.9)$ & $96.6(92.5-98.5)$ & $90.9(84.2-94.9)$ & $75.7(42.5-91.4)$ \\
\hline
\end{tabular}

$\overline{C I}$, Confidence interval; $A V$, aortic valve; $P V$, pulmonary valve. * Greater than mild. $\dagger$ Moderate or severe pulmonary valve insufficiency and/or peak systolic gradient $\geq 40 \mathrm{~mm}$ Hg.

\section{Pathology of Explanted Pulmonary Valve Autograft}

Eleven pulmonary valve autografts were explanted: 1 was normal (explanted 11 days after surgery) and 10 had gross and histologic abnormality (explanted from 1 to
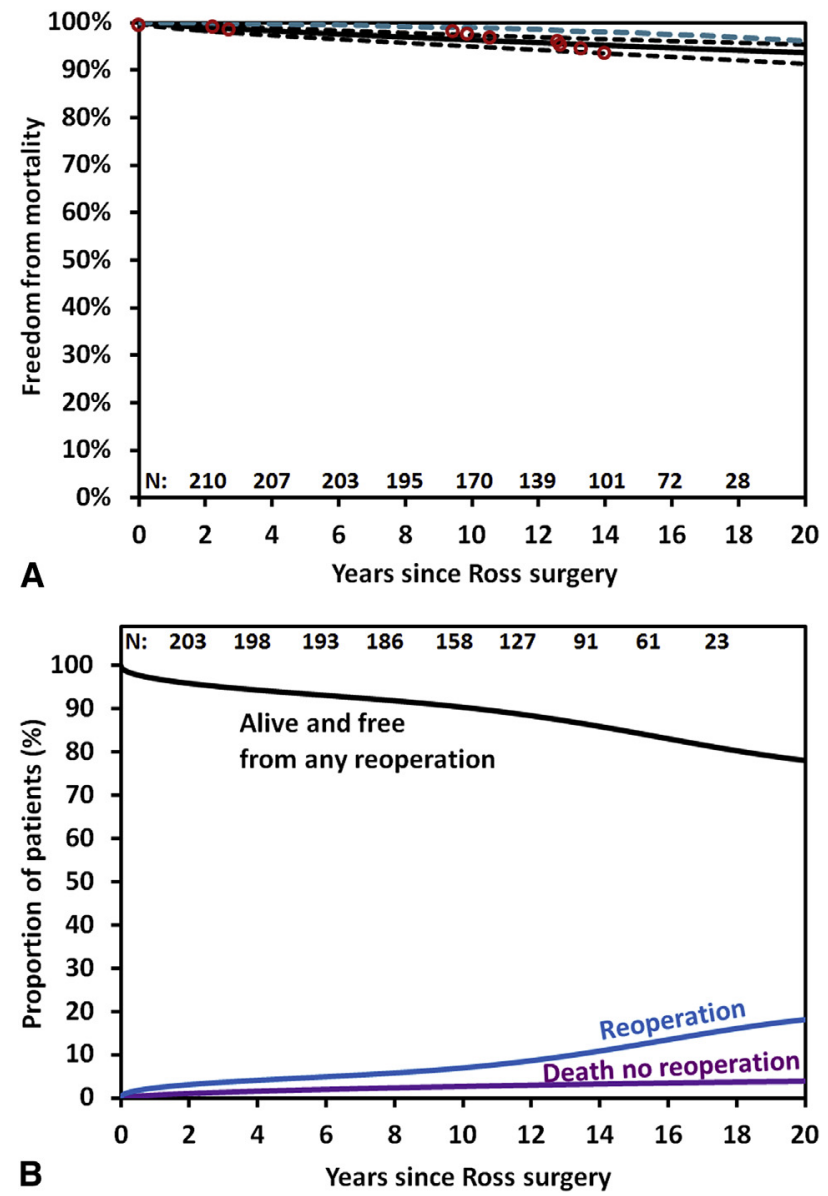

FIGURE 1. A, Survival estimates of patients who underwent the Ross procedure, including those who no longer had the pulmonary autograft (black solid line) with $95 \%$ confidence limits (black dotted line) and that of the general population matched for age and sex (dotted blue line). $\mathrm{B}$, Reoperation-free survival and the competing risks for any reoperation on the pulmonary autograft or homograft and death.
17 years [median, 8.7 years] after surgery). The cusps had gross evidence of degenerative changes with thinning and stretching of the cusps and elongation of the free margins with prolapse. Four valves had cusp tears in the commissural areas. Microscopy showed fragmentation of the fibrous and elastic tissues and distortion of the normal histology. Their basal region showed thickening due to pannus.

\section{Event-Free Survival and Late Functional Class}

Figure 1, $B$, shows pulmonary autograft or pulmonary homograft reoperation-free survival and the competing risk of reoperation and death. The estimates of reoperation-free survival at various time intervals are shown in Table 2 . At the latest follow-up contact 202 patients were alive and 191 still had their pulmonary autograft in place. Overall, $180(89 \%)$ patients were in New York Heart Association functional class I, $18(9 \%)$ in class II, and 4 $(2 \%)$ in class III.

\section{Echocardiographic Studies}

AI. Twenty-six patients developed more than mild AI (reported as mild to moderate or greater degree). Thirteen patients with AI had reoperation because of symptoms (3 patients), dilation of the aortic root (2 patients), or dilation of the left ventricle ( 8 patients). In addition, 1 asymptomatic patient was scheduled for elective aortic valve surgery at the time of the final follow-up contact because of AI and impaired left ventricular systolic function. Table 2 shows the freedom from AI greater than mild at various time intervals. The following variables increased the risk of late AI: preoperative AI (HR, 2.3; $95 \%$ CI, $0.9-5.5 ; P=.06$ ), aortic annulus $\geq 28 \mathrm{~mm}$ (HR, 2.37; 95\% CI, 1.02-5.52; $P=.04$ ), and indexed diameter of the aortic annulus (HR, $1.044 / \mathrm{mm} ; 95 \%$ CI, 1.006-1.085; $P=.02$ ). Figure 3 shows the association between preoperative aortic annulus diameter and the development of AI.

Dilation of the pulmonary autograft. Progressive dilation of the pulmonary autograft sinus defined as 

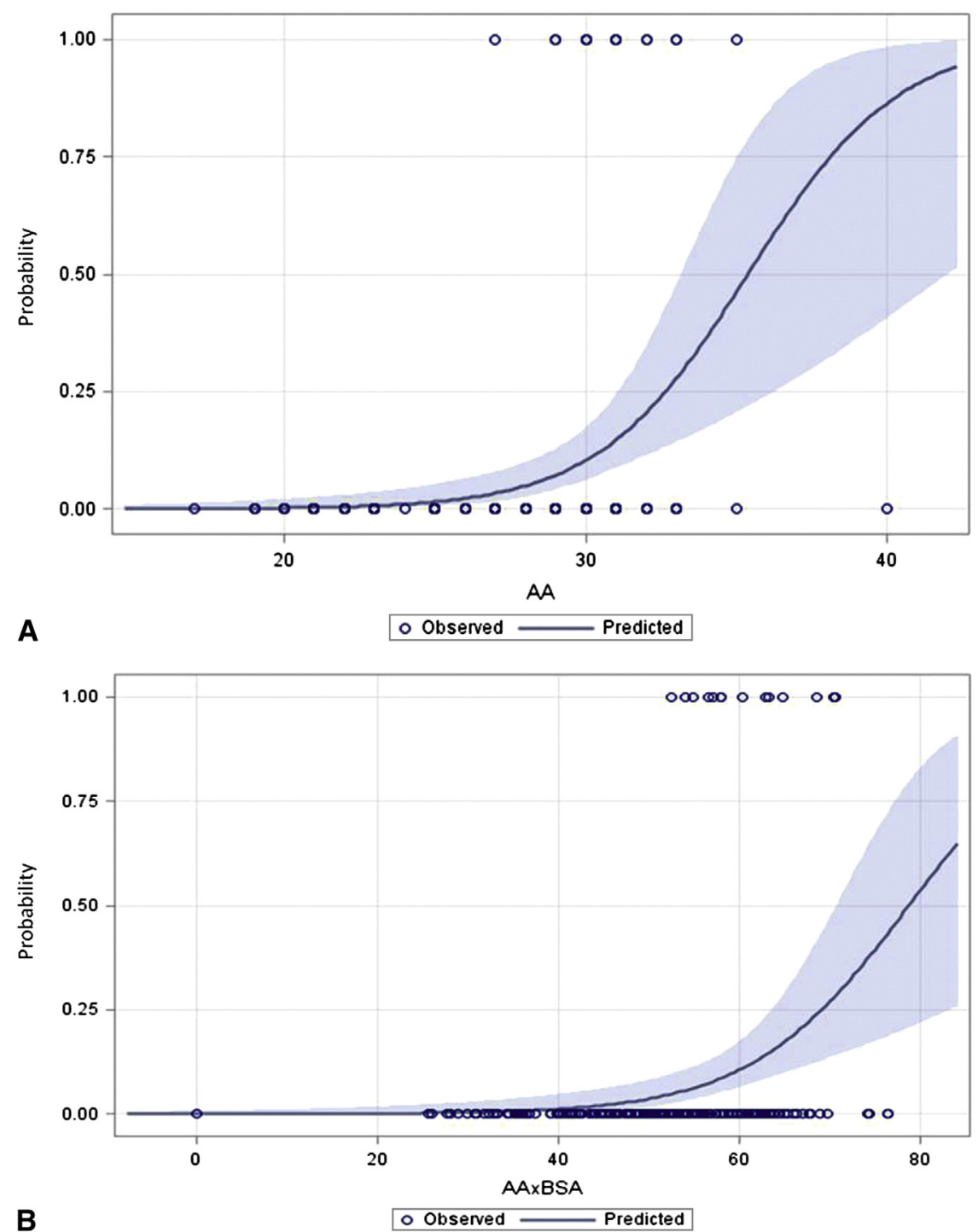

FIGURE 2. A, Association between the probability of reoperation on the neo-aortic valve and the diameter of the aortic annulus $(A A)$. The cut-off point was $\geq 28 \mathrm{~mm}$. B, Association between the probability of reoperation on the neo-aortic valve and the diameter of the AA adjusted for body surface area (BSA). The cut-off point was at $15 \mathrm{~mm} / \mathrm{m}^{2}(P=.001)$. Shaded area represents $95 \%$ confidence intervals.

diameter $\geq 39 \mathrm{~mm}$ occurred in 35 patients. The diameter increased to 39 to $44 \mathrm{~mm}$ in 24 patients, 45 to $49 \mathrm{~mm}$ in 7 patients, and $>49 \mathrm{~mm}$ in 4 patients. Progression of aortic sinus size was faster after the technique of root replacement than after the technique of subcoronary implantation $(0.149$ $\pm 0.058 \mathrm{~mm} /$ year vs $0.122 \pm 0.060 \mathrm{~mm} /$ year; $P=.01$ ). Dilation of the neo-aortic root was associated with the development of AI as seen in Figure 4. Table 2 shows the freedom from dilation $>44 \mathrm{~mm}$ of the pulmonary autograft at various times intervals.

Pulmonary homograft dysfunction. Pulmonary valve dysfunction was defined as pulmonary valve insufficiency of moderate or severe degree and/or a peak systolic gradient $\geq 40 \mathrm{~mm} \mathrm{Hg}$. Twenty-five patients developed pulmonary homograft dysfunction but only 8 have undergone reintervention. The remaining patients continue to be assessed for the development of symptoms and/or right ventricular dilation/dysfunction to determine the timing for reintervention. The freedom from reoperation on the pulmonary homograft and the freedom from pulmonary homograft dysfunction at various times intervals is shown in Table 2. There were no predictors of pulmonary valve dysfunction by multivariable analysis and no statistically significant associations by univariable analysis.

\section{DISCUSSION}

Aortic valve replacement is a palliative treatment for aortic valve disease and the Ross procedure is no exception. We have been examining a cohort of Ross patients 

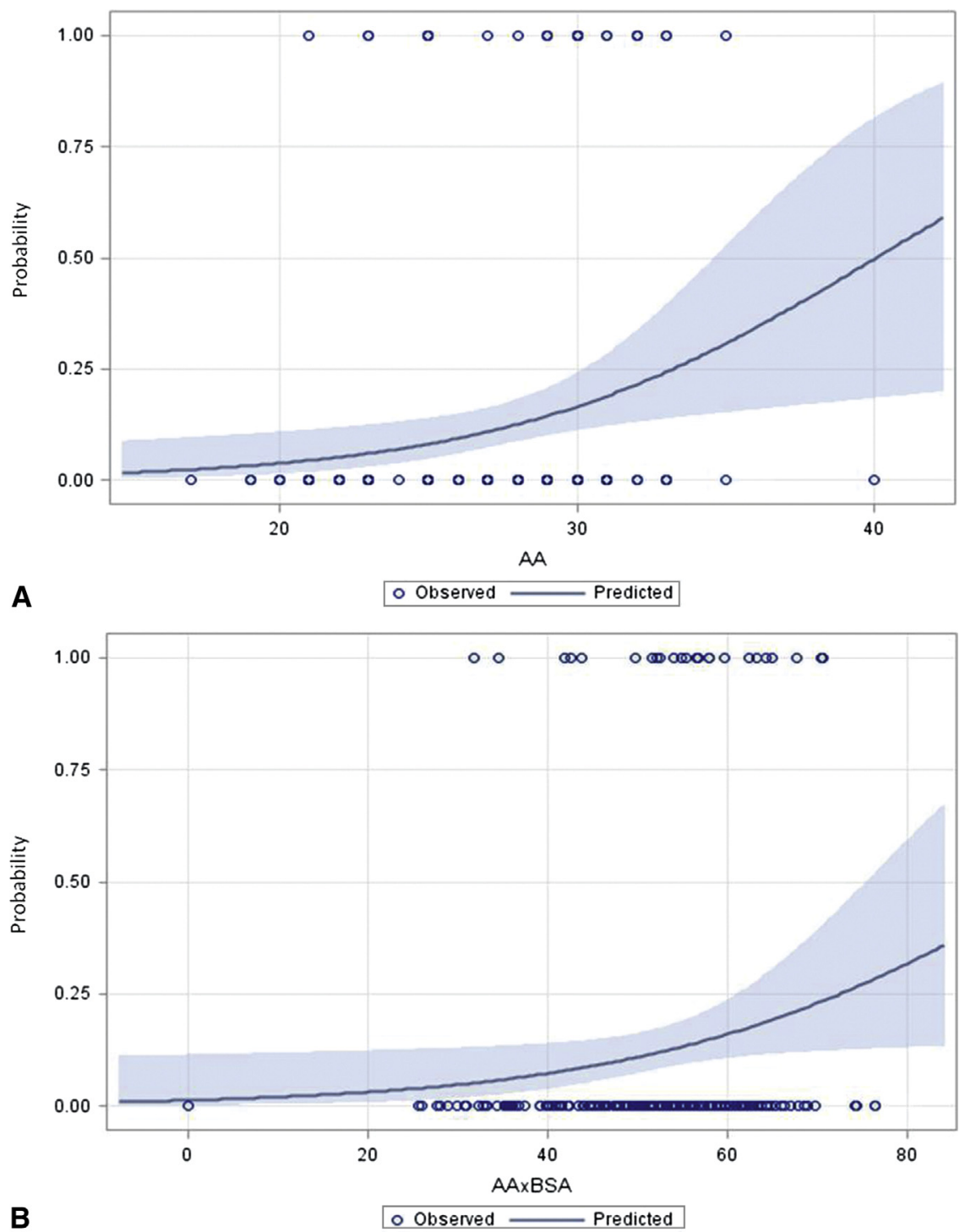

FIGURE 3. A, Association between diameter of the aortic annulus $(A A)$ index and the probability of postoperative development of aortic insufficiency $(P=.02)$. B, Association between the diameter of the AA and the probability of postoperative development of aortic insufficiency adjusted for body surface area $(B S A)$. Shaded area represents $95 \%$ confidence intervals.

prospectively during the past 24 years to determine the predictors of poor outcomes. Our data suggest that survival after the Ross procedure during the first 2 decades of observation is excellent, even including patients who had reoperations as it was done in this report.

Mokhles and colleagues ${ }^{20}$ published a case-match study of 253 patients who had isolated aortic valve replacement with mechanical valve with a highly specialized anticoagulation self-management operated on in Bad Oeynhausen, Germany (mean age, 48 years; mean follow-up, 6.3 years) and 253 patients who underwent the Ross procedure from the German-Dutch Ross Registy (mean age, 47.3 years; mean follow-up, 5.1 years) showing no difference in survival up to 8 years.
The Ross procedure is a complex operation that transforms aortic valve disease into combined aortic and pulmonary valve disease. Therefore, if a young adult in need for aortic valve replacement is willing to take warfarin permanently, especially if able of self-monitoring the anticoagulation, we believe that a mechanical valve is a more reasonable alternative than the Ross procedure. However, if anticoagulation is to be avoided the outcomes of the Ross procedure should be compared with other types of tissue valves. In our series of patients with the Ross procedure the freedom from reoperation for any reason on the pulmonary autograft was $81.8 \%$ at 20 years, the freedom from reoperation on the pulmonary homograft was $92.7 \%$, and the combined risk of reoperation or 


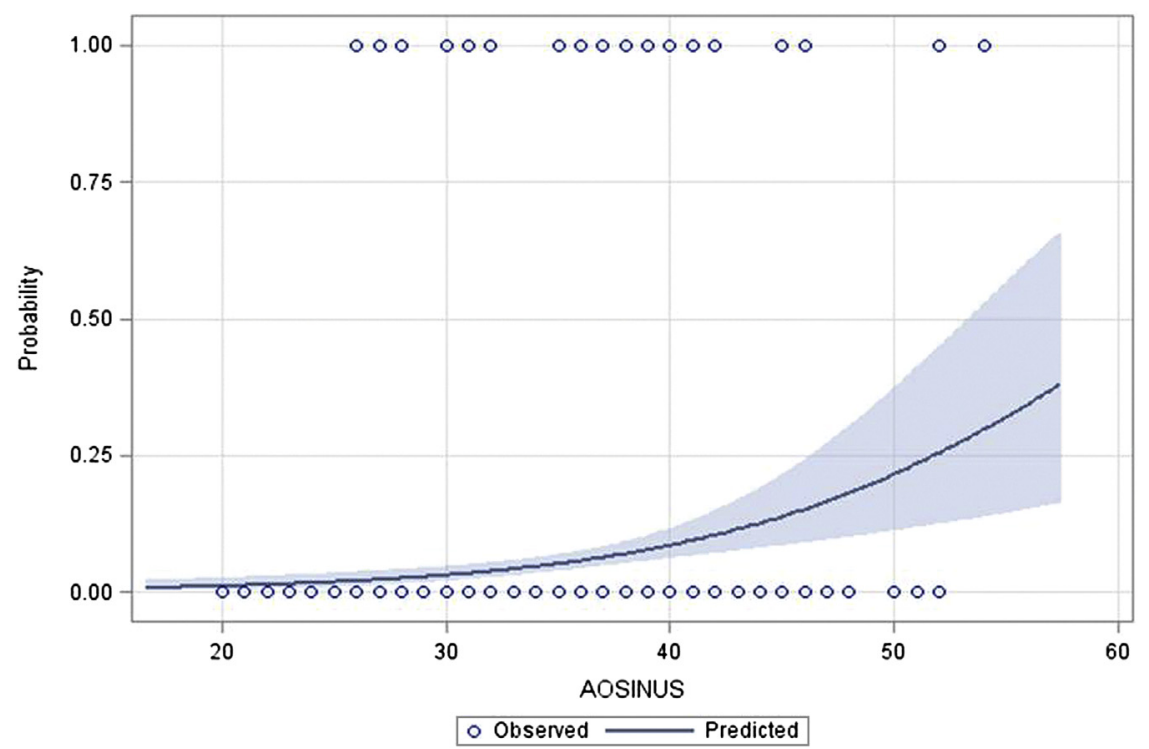

FIGURE 4. Association between dilatation of the neo-aortic root (AOSINUS) and the development of aortic insufficiency. Shaded area represents $95 \%$ confidence intervals.

percutaneous interventions on these 2 valves was $77.9 \%$. These outcomes are much better than those obtained after aortic valve replacement with bioprosthetic aortic valves or aortic valve homografts in patients of similar age. ${ }^{21-23}$ A randomized clinical trial on aortic valve replacement with pulmonary autograft versus aortic homograft conducted by Sir Magdi Yacoub ${ }^{23}$ showed a survival benefit in patients who had the Ross at 10 years. Therefore, if warfarin is to be avoided in young patients, particularly in women during childbearing years, the Ross procedure is an excellent alternative. ${ }^{24}$

Our results compare to those reported by Charitos and colleagues from Lubeck, Germany. ${ }^{25}$ They examined a cohort of 203 patients operated on from 1994 through 2001 with a mean age was 47.2 years, a minimum followup of 10 years, and reported a freedom from reoperation on the pulmonary autograft of $89.6 \%$ at 15 years. $^{2}$ On the other hand, Mokhles and colleagues ${ }^{4}$ from Rotterdam, The Netherlands, reported freedom from reoperation on the pulmonary autograft of only $51 \%$ at 18 years but their patients had a mean age of 20.9 years and almost one-half were aged $<18$ years, which is much lower than Charitos and colleagues ${ }^{25}$ and our patients. The reasons for these differences in outcomes are unclear. Probably patients' age, aortic valve pathology, operative technique, and surgeon's experience played a role. ${ }^{10}$ In Mokhles' series of 161 patients, ${ }^{4} 6$ surgeons performed the operations over a 22-year interval and used mostly the technique of aortic root replacement. In the series reported by Charitos and colleagues, ${ }^{25} 203$ patients were operated on over an 8 -year interval and probably by a couple of surgeons who used exclusively the technique of subcoronary implantation. As with any complex operative procedure, repetition makes perfect and a certain volume of Ross procedures is needed to develop expertise. In our series, all operations were performed by 1 surgeon over a 15-year interval and both techniques of implantation were used depending on the surgeon's interpretation of the aortic root pathology in relation to the normal pulmonary valve as described in "Methods." We did not find an association between the implantation technique and the risk of reoperation on the pulmonary autograft. However, dilated aortic annulus, preoperative AI, and male sex were associated with increased risk of reoperation on the pulmonary autograft. Several other investigators have identified preoperative $\mathrm{AI}$ as a predictor of reoperation on the pulmonary autograft. ${ }^{4-5,7,25}$ In the series described by Charitos and colleagues, ${ }^{25} 9$ of 14 patients who required reoperation on the pulmonary autograft had preoperative $\mathrm{AI}$ and an aortic annulus $>28 \mathrm{~mm}$.

The main indication for reoperation on the pulmonary autograft is the development of AI. In our patients the freedom from AI greater than mild at 10, 15, and 20 years was $90.3 \%, 88.7 \%$, and $62.6 \%$, respectively. AI appears to be progressive after the Ross procedure. A dilated aortic annulus $\left(>28 \mathrm{~mm}\right.$ in large patients or $\geq 15 \mathrm{~mm} / \mathrm{m}^{2}$ in smaller patients), and preoperative AI were independent predictors of late AI. The technique of implantation of the autograft was not associated with an increased risk of AI but dilation of the aortic root was by univariable analysis. Because the technique of aortic root replacement was associated with greater degree of dilatation of the aortic root than the subcoronary or inclusion techniques it is possible that with a larger sample size the implantation 
technique would have been a factor in the development of postoperative $\mathrm{AI}$ in our series. We believe that both techniques are useful and continue to use the inclusion technique when the aortic root is larger than the pulmonary root and the technique of aortic root replacement when the aortic root is too small or the coronary arteries' orifices are close to the annulus for safe subcoronary implantation. As we mentioned previously ${ }^{27}$ we firmly believe that dilated aortic annulus in patients with bicuspid aortic valve is a marker for connective disorder that is probably present in the pulmonary valve and we believe that the Ross should not be performed in patients with aortic annulus index $\geq 15 \mathrm{~mm} / \mathrm{m}^{2}$.

An Achilles' heel of the Ross procedure is the pulmonary homograft, which in our experience almost one-half of all cases developed echocardiographic evidence of dysfunction 20 years after implantation. The freedom from pulmonary homograft reintervention was high at $92.7 \%$ at 20 years but many other patients had echocardiographic signs of valve dysfunction and continue to be monitored to determine the timing for reintervation. These findings are consistent with those of other investigators. ${ }^{5,10,25}$ Young age has been associated with increased risk of failure of the pulmonary homograft, ${ }^{5,10}$ but it was not the case in our series probably because our patients mean age was 34 years and we had none under 16 years of age.

Stulak and colleagues ${ }^{15}$ from the Mayo Clinic raised concerns about the complexity and extensiveness of reoperations on patients with failed Ross procedure. They performed 144 procedures in 56 patients with failed Ross and although they had only 1 operative death, 4 other patients died within a mean follow-up of 8 months. ${ }^{15}$ Because most patients in that series had the initial operation outside of the Mayo Clinic, the authors could not estimate the overall burden of reoperation on patients who had the Ross procedure. The fact is that in centers with large experience with the Ross procedure reoperations carried a very low operative mortality and morbidity. ${ }^{4,10,13,14,26}$ Mokhles and colleagues ${ }^{15}$ in Rotterdam, The Netherlands, reoperated on 57 patients who had the Ross procedure without operative mortality. We agree that reoperation for failed Ross procedure is complex and often extensive but it can be safely performed in experienced centers as it was at Mayo Clinic.

Although our patients were prospectively followed and valve function was sequentially assessed by echocardiography in most patients, our study has several limitations. The number of patients was relatively small and so was the number of adverse events, limiting the value of multivariable models. Two different types of implantation techniques were used and this further reduced the number of patients in each subgroup to determine the importance of the implantation technique on outcomes. In addition, most of our patients had congenital aortic valve disease and presented with stenosis, insufficiency or both lesions.
Finally, all operations were performed by 1 surgeon and the results may not be generalizable.

\section{CONCLUSIONS}

Aortic valve replacement with pulmonary autograft is a complex and controversial operative procedure, yet we believe that young adults who do not wish to have a mechanical valve do very well after the Ross procedure as long as their aortic annulus is not dilated.

\section{References}

1. Takkenberg JJM, Klieverik LMA, Schoof PH, van Suylen RJ, van Herwerden LA, Zondervan PE, et al. The Ross procedure: a systematic review and meta-analysis. Circulation. 2009;119:222-8

2. David TE. The Ross procedure at the crossroads. Circulation. 2009;119:207-9.

3. Klieverik LM, Takkenberg JJ, Bekkers JA, Roos-Hesselink JW, Witsenburg M, Bogers AJ. The Ross operation: a Trojan horse? Eur Heart J. 2007;28: 1993-2000.

4. Mokhles MM, Rizopoulos D, Andrinopoulou ER, Bekkers JA, RoosHesselink JW, Lesaffre E, et al. Autograft and pulmonary allograft performance in the second post-operative decade after the Ross procedure: insights from the Rotterdam Prospective Cohort Study. Eur Heart J. 2012;33:2213-24.

5. Elkins RC, Thompson DM, Lane MM, Elkins CC, Peyton MD. Ross operation: 16-year experience. J Thorac Cardiovasc Surg. 2008;136:623-30.

6. David TE, Woo A, Amrstrong S, Maganti M. When is the Ross operation a good option to treat aortic valve disease? J Thorac Cardiovasc Surg. 2010; 139:68-75

7. Ryan WH, Prince SL, Culica D, Herbert MA. The Ross procedure performed for aortic insufficiency is associated with increased autograft reoperation. Ann Thorac Surg. 2011:911:64-9.

8. Brown JW, Fehrenbacher JW, Ruzmetov M, Shahriari A, Miller J, Turrentine MW. Ross root dilation in adult patients: is preoperative aortic insufficiency associated with increased late autograft reoperation? Ann Thorac Surg. 2011;92:74-81.

9. Brown JW, Ruzmetov M, Shahriari A, Rodefeld MD, Turrentine MW, Mahomed Y. The Ross full root replacement in adults with bicuspid aortic valve disease. J Heart Valve Dis. 2011;20:332-9.

10. Charitos EI, Takkenberg JJ, Hanke T, Gorski A, Botha C, Franke U, et al. Reoperations on the pulmonary autograft and pulmonary homograft after the Ross procedure: an update on the German Dutch Ross Registry. $J$ Thorac Cardiovasc Surg. 2012;144:813-21

11. David TE, Omran A, Ivanov J, Armstrong S, de Sa MP, Sonnenberg B, et al. Dilation of the pulmonary autograft after the Ross procedure. J Thorac Cardiovasc Surg. 2000;119:210-20

12. Takkenberg JJ, van Herwerden LA, Galema TW, Bekkers JA, Kleyburg Linkers VE, Eijkemans MJ, et al. Serial echocardiographic assessment of neo-aortic regurgitation and root dimensions after the modified Ross procedure. J Heart Valve Dis. 2006;15:100-6.

13. de Kerchove L, Rubay J, Pasquet A, Poncelet A, Ovaert C, Pirotte M, et al. Ross operation in the adult: long-term outcomes after root replacement and inclusion techniques. Ann Thorac Surg. 2009;87:95-102.

14. Luciani GB, Lucchese G, De Rita F, Puppini G, Faggian G, Mazzucco A. Reparative surgery of the pulmonary autograft: experience with Ross reoperations. Eur J Cardiothorac Surg. 2012;41:1309-14.

15. Stulak JM, Burkhart HM, Sundt TM III, Connolly HM, Suri RM, Schaff HV, et al. Spectrum and outcome of reoperations after the Ross procedure. Circulation. 2010;122:1153-8

16. David TE, Omran A, Webb G, Rakowski H, Armstrong S, Sun Z. Geometric mismatch the aortic and pulmonary roots causes aortic insufficiency after the Ross procedure. J Thorac Cardiovasc Surg. 1996;112:1231-9

17. Cujec B, David T, Wilansky S, Pollick C. Colour flow imaging in severe mitral and aortic regurgitation. Can J Cardiol. 1988;4:341-6.

18. Zoghbi WA, Enriquez-Sarano M, Foster E, Grayburn PA, Kraft CD, Levine RA, et al. Recommendations for evaluation of the severity of native valvular regurgitation with two-dimensional and Doppler echocardiography. J Am Soc Echocardiogr. 2003;16:777-802.

19. Statistics Canada. Life tables. Available at: http://www.statcan.gc.ca/pub/84537-x/4064441-eng.htm. Accessed August 31, 2013. 
20. Mokhles MM, Körtke H, Stierle U, Wagner O, Charitos EI, Bogers JJC, et al. Survival comparison of the Ross procedure and mechanical valve replacement with optimal self-management anticoagulation therapy: propensity-matched cohort study. Circulation. 2011;123:31-8.

21. David TE, Armstrong S, Maganti M. Hancock II bioprosthesis for aortic valve replacement: the gold standard of bioprosthetic valves durability? Ann Thorac Surg. 2010;90:775-81

22. Smedira NG, Blackstone EH, Roselli EE, Laffey CC, Cosgrove DM. Are allografts the biologic valve of choice for aortic valve replacement in nonelderly patients? Comparison of explantation for structural valve deterioration of allograft and pericardial prostheses. J Thorac Cardiovasc Surg. 2006;131: 558-96.

23. Ismail El-Hamamsy I, Eryigit Z, Stevens LH, Sarang Z, George R, Clark L, et al. Long-term outcomes after autograft versus homograft aortic root replacement in adults with aortic valve disease: a randomised controlled trial. Lancet. 2010;376: 524-31.

24. Heuvelman HJ, Arabkhani B, Cornette JM, Pieper PG, Bogers AJ, Takkenberg JJ, et al. Pregnancy outcomes in women with aortic valve substitutes. Am J Cardiol. 2013;111:382-7.

25. Charitos EI, Stierle U, Hanke T, Schmidtke C, Sievers HH, Richardt D. Longterm results of 203 young and middle-aged patients with more than 10 years of follow-up after the original subcoronary Ross operation. Ann Thorac Surg. 2012:93:495.

26. David TE. Reoperations after the Ross procedure. Circulation. 2010;122: 1139-40.

27. de Sa M, Moshkovitz Y, Butany J, David TE. Histologic abnormalities of the aorta and pulmonary trunk in patients with aortic valve disease: clinical relevance to the Ross procedure. J Thorac Cardiovasc Surg. 1999;118: 588-94.

\section{Discussion}

Dr Nicholas T. Kouchoukos (St Louis, Mo). Dr David and his colleagues have presented important outcomes data for 212 patients who underwent the Ross procedure and have been followed for a median of 12.8 years and for up to 20 years. The significant positive findings include excellent long-term survival, essentially equal to that for an age- and sex-matched population, and extremely low rates of thromboembolism and endocarditis.

The concerning findings relate to the need for reoperation on the neo-aortic valve and progression of both aortic regurgitation and pulmonary allograft dysfunction, both stenosis and regurgitation, particularly in the second decade of follow-up, irrespective of the need for reoperation. Although $82 \%$ of patients had not required reoperation on the neo-aortic valve at 20 years, only $63 \%$ were free of more than mild aortic regurgitation at that time interval. Similarly, although $93 \%$ had not required reoperation on the pulmonary allograft at 20 years, only $54 \%$ were free of either moderate or severe pulmonary valve regurgitation or stenosis $>40 \mathrm{~mm} \mathrm{Hg}$.

These important observations suggest that freedom from reoperation is an inadequate predictor of successful outcome after the Ross procedure. The rates of deterioration in function of both the autograft and the allograft were substantially greater in the second decade of follow-up when compared with the first, and one can only speculate, because these were relatively young patients, what will happen in the third decade and beyond. The effects of these changes in valvular function on overall cardiac performance were not reported in this study but are of obvious importance when one is considering the Ross procedure for a particular patient, especially one who is young.
Another important issue is the technique of implantation of the autograft. Your study demonstrated no difference in the need for reoperation for neo-aortic valve regurgitation between the root replacement and the subcoronary or root inclusion techniques. However, they were performed for somewhat different indications. Despite this difference, dilation of the aortic sinuses occurred with both techniques, although at a higher rate with the root replacement technique. You have speculated in the past that reimplantation of the autograft within the aortic root may be associated with better long-term outcomes. However, this was not observed in your presentation today. I have several questions and I will ask them separately.

External reinforcement techniques have been proposed and used in an attempt to prevent aortic root dilation and regurgitation. Is there a role for these modifications to reduce the frequency of regurgitation and reoperation?

Dr Tirone E. David (Toronto, Ontario, Canada). I don't believe so. I did in the past, but as my experience has increased it doesn't look like the operative technique plays a role in the failure of this operation. It is more a marker that certain patients have. I believe that dilation of the aortic annulus is a marker for connective tissue disorder, and we should avoid the Ross procedure in these patients.

I should add that in our failures due to aortic insufficiency we could not save the aortic valve. They all showed signs of degenerative disease, indicating that, indeed, they are predestined to fail under adverse conditions such as the systemic circulation.

Dr Kouchoukos. Dilation of the aortic root is not an infrequent late occurrence and was present in 35 patients in your series. At 10 years, $25 \%$ of patients had dilation $>4.5 \mathrm{~cm}$. Dissection of the dilated aortic root has been reported in a small number of patients. Would you consider elective operation in patients who have enlarged aortic roots, and if so, at what diameter?

Dr David. I no longer offer the Ross procedure to patients who have an annulus $>28 \mathrm{~mm}$. I tell them that in our hands the failure rate is pretty high and we prefer to use an alternative. Having said that, for female patients in their childbearing years who do not want a mechanical valve, the Ross is a reasonable alternative. Perhaps those patients should have some sort of external reinforcement, preferably their own aortic root. But in our experience it is not the sinus that is the problem. The pulmonary cusps fail when placed in the aortic position, suggesting that annuloaortic ecstasia is a marker for something more serious than a dysfunctional aortic valve.

Dr Kouchoukos. What do you do for those patients who have developed dilation, with root $4.5 \mathrm{~cm}$ or greater?

Dr David. Most had a bicuspid aortic valve and an incompetent valve at the time of the operation.

Dr Kouchoukos. When would you recommend elective replacement of the enlarged root to avoid problems with further enlargement or dissection? Ever?

Dr David. We used the same criteria for native aortic root aneurysm; that is, recommend surgery when the diameter exceeds $50 \mathrm{~mm}$. I don't know if it is justifiable to operate earlier because most of our patients who developed dilation of the neo-aortic root had a dilated aortic annulus and they may have degenerative changes in the cusps of the autograft precluding an aortic valve sparing operation. 
Dr Kouchoukos. In your practice do you still recommend using the Ross operation? If so, who do you consider to be an ideal patient?

Dr David. A man with aortic stenosis and an annulus $<28 \mathrm{~mm}$. In women, to be quite honest, the lesion doesn't matter. I don't know why. In the 98 women we studied all have normally functioning pulmonary valves at 20 years. In other words, any women or young male patients with aortic stenosis and normal annulus.

Dr Gosta B. Pettersson (Cleveland, Ohio). I would like to ask you about your choice of procedure for the reoperations. I noticed that you had done only 1 reimplantation procedure. In the Ross community there is a lot of enthusiasm for doing the reimplantation procedure for the reoperation to salvage the autograft in aortic position. You also mentioned that the leaflets are not normal. I agree with your observation, and, as you know, I have favored the Ross reversal procedure as a way to salvage the autograft. So my first question: What is your choice of reoperation procedure?

I also have a follow up question: Would you consider earlier reoperation to salvage more autograft valves in aortic position by reoperating earlier to have a better chance of being able to do reimplantation?

Dr David. In our cohort most had abnormal cusps at reoperation that precluded an aortic valve sparing. Often 2 or 3 cusps were torn, and the histology showed scar tissue and fragmentation of the elastic, suggestive of a degenerative process. And because they all came from patients with bicuspid aortic valve with dilated aortic annulus, I have to make the assumption that it is unwise to repair the cusps to save the autograft.

My experience is largely with bicuspid aortic valves. I don't have experience with rheumatic disease. They may behave differently

Dr Pettersson. What do you think about the reverse Ross operation?

Dr David. I commend you on that, as I know you have done it. The Ross operation is a difficult operation. To reverse it must be even more difficult. I imagine it can be done and I will try the next time I reoperate on a failed Ross.

Dr D. Craig Miller (Stanford, Calif). I did not hear an answer to Nick's specific question. At what size Ross root aneurysms when done as a root replacement do you recommend operation? Has anyone ever seen a Ross root aneurysm rupture or dissect?

Dr David. I have never seen it. A friend showed me images of a Ross with a root of $55 \mathrm{~mm}$ and the valve was fairly competent because he had reinforced both the annulus and the sinotubular junction, but the sinus ruptured and he had to operate on the patient as an emergency.

Dr Miller. When do you reoperate on patients who are dilating?

Dr David. At $50 \mathrm{~mm}$ because I am hoping to save the valve, but I didn't in most of them because of bad cusps.

Dr Miller. In your analysis you had 2 techniques, an inclusion sleeve and a root replacement. Nearly half of your patients were done in the proper way, a subcoronary scallop, the real way that this operation was originally introduced, and Hans Sievers has the best results in the world. Was that variable inspected in terms of your 2 dependent outcome variables?

Dr David. The technique was not a predictor of reoperation or aortic insufficiency. It was in an early analysis, but as the follow-up increased, it doesn't seem to be a predictor.

There are certain technical details of root replacement that are the reason other surgeons encounter dilation and failure. Suturing the autograft, with an annulus that is entirely muscular, in a supra-annular position is doomed to fail. That annulus is going to dilate. If you put the muscle inside the outflow tract where nature made the native aortic annulus, I don't believe it dilates very much. So perhaps the outcomes have more to do with how you perform the root replacement than with the subcoronary versus root replacement technique.

Dr Miller. Did you examine the third technique, something short of root replacement, in your statistical analysis, freehand scalloped? Did you examine all 3 ways?

Dr David. No. We grouped them together because I performed root inclusion more often than subcoronary. If the root was dilated enough, I simply opened the noncoronary sinus down to the annulus, put the pulmonary inside the native root, and closed it either primarily or with a patch. That is my root inclusion technique. I only use the subcoronary position in patients with an entirely normal aortic annulus and sino-tubular junction, which very few patients have. 